\title{
Histological study of implantation in the Natal clinging bat (Miniopterus schreibersii natalensis)
}

\author{
M. van der Merwe \\ Mammal Research Institute, University of Pretoria, Pretoria 0002, South Africa
}

\begin{abstract}
Summary. In the Natal clinging bat, Miniopterus schreibersii natalensis, implantation is centric and superficial in the right uterine horn. The blastocyst implants during the bilaminar stage with the inner cell mass orientated antimesometrially. During the preimplantation period the blastocyst becomes completely enclosed by uterine mucosae with the trophoblast in close contact with the surrounding uterine epithelium. Just before implantation the trophoblast becomes bilaminar over the greater part of the embryonic hemisphere of the blastocyst. The uterine epithelium is very persistent and parts were still present mesometrially although penetration of the uterine endometrium had already occurred on the antimesometrial side.
\end{abstract}

\section{Introduction}

In mammals considerable variation occurs in the interval between fertilization and the conceptus entering the uterus, and the interval between this event and implantation (for review, see Wimsatt, 1975). In some mammals, however, in which delayed implantation occurs, the period between conception and implantation is extended (Daniel, 1970; Wimsatt, 1975). This phenomenon is also found in bats although not so commonly (Flemming, 1971) and occurs mainly in the hibernating members of the genus Miniopterus (Wimsatt, 1969, 1975). In the Natal clinging bat ( $M$. schreibersii natalensis) there is a delay of 4 months from the time of conception until the blastocyst eventually implants (van der Merwe, 1979, 1980).

Implantation begins after loss of the zona pellucida when the conceptus has reached the relevant site in the uterus (Potts, 1969). The implanting blastocyst is positioned according to a number of determinants which are species specific (Kirby, Potts \& Wilson, 1967). In most eutherian mammals the first point of trophoblastic attachment in relation to the embryonic disc is fairly consistent within orders and suborders (Mossman, 1971; Wimsatt, 1975). There appear to be exceptions amongst the insectivores and bats in which several different orientation patterns have been observed (Mossman, 1971; Wimsatt, 1975). Although comparative information on blastocyst-endometrium relationships during the preimplantation phases in bats is meagre, vespertilionid bats appear to have similar patterns. At present information is available for 7 representatives of this family and in all of them the basic implantation characteristics (i.e. site of initial trophoblastic attachment, orientation of the inner cell mass and depth of implantation) are similar (for review, see Rasweiler, 1979). The purpose of the present study was to investigate some of these events in the Natal clinging bat with special emphasis on the changes occurring in the uterus and especially the blastocyst during the period just before and during implantation.

\section{Materials and Methods}

The present study is based on 30 reproductive tracts of Natal clinging bats ( $M$. s. natalensis) collected during 1979 in Schurveberg Cave No. $1\left(25^{\circ} 48^{\prime} \mathrm{S}, 28^{\circ} 01^{\prime} \mathrm{E}\right)$ situated on the southern 
Transvaal Highveld. These collections were made during the months of July and August when implantation in these bats is known to occur.

In the laboratory the females were killed with chloroform and the bicornuate uterus was excised just behind the bladder and fixed in Bouin's fluid. Before the uteri were fixed they were first placed on square pieces of glass (cut from standard microscope slides) to which the tissue adhered, thus preventing curling or folding of the horns when placed carefully in the fixative. All

\section{PLATE 1}

Fig. 1. Bilaminar blastocyst completely enclosed by uterine mucosae with the trophoblast conforming closely to the surrounding uterine epithelium (u. ep.). The space separating the two layers is an artefact of fixation. The trophoblast and endoderm layers are in close contact with each other, except in the embryonic region (also see insert) where they are separated by the inner cell mass. The part of the trophoblast layer covering the inner cell mass on the outside and the part of the endodermic layer covering it on the inside are indicated by arrows.

Fig. 2. Blastocyst almost completely enclosed in a pocket, formed mainly by the uterine mucosae on the antimesometrial side, while the uterine lumen is nearly completely obliterated. The inner cell mass (arrowed) is, unusually, mesometrially orientated in this specimen.

\section{PLATE 2}

Fig. 3. Embryonic pole of a completely enclosed blastocyst just before proliferation of the trophoblast over the embryonic hemisphere. The uterine epithelium (u. ep.) is still present. In this specimen the inner cell mass with a centrally situated primitive amniotic cavity (p.a.c.) is already starting to flatten, thereby exposing the embryonic disc. The primitive amnion (arrowed) becomes stretched and attenuated underneath the overlying trophoblast (tr.). In this section cellular debris is not conspicuous within the primitive amniotic cavity but is conspicuous in other sections (insert) of the same specimen.

Fig. 4. Bilaminar blastocyst with embryonic disc (em. disc) antimesometrially orientated after implantation. Over the entire embryonic hemisphere the syncytiotrophoblast (arrowed) has been established. On the mesometrial side (also see insert) the trophoblast does not actively penetrate the endometrium but forms papillae (double-headed arrow) penetrating the mouths of glands. In this section part of the uterine epithelium (triple-headed arrow) has been pulled away from the underlying endometrium which clearly illustrates its presence mesometrially although it has been completely destroyed antimesometrially.

\section{PLATE 3}

Fig. 5. Embryonic pole of an implanting bilaminar blastocyst showing the start of trophoblast proliferation. For most of its length over the embryonic hemisphere the trophoblast layer (tr.) is still unilaminar except for the embryonic region where it is proliferating in places. This action causes trophoblast cells (arrowed) to move between the original trophoblast layer (tr.) and overlying uterine epithelium (u. ep.). Uterine glands are still present but are degenerating, as indicated by the presence of luminal cellular debris (double-headed arrow).

Fig. 6. Section of the embryonic hemisphere of an implanting blastocyst (inner cell mass not visible). The trophoblast layer, underlying the uterine epithelium (u. ep.), is bilaminar with both the outer trophoblast layer (o. tr. 1.) and the cytotrophoblast (cyt. tr.) having a cellular arrangement. The endoderm (end.) with its flattened nuclei is so closely adhered to the cytotrophoblast that it is nearly indistinguishable in places.

Fig. 7. Implanted blastocyst showing the syncytiotrophoblast (arrowed) penetrating the endometrium. The invading syncytiotrophoblast does not appear to be cellular although the cellular structure of the cytotrophoblast (cyt. tr.) is maintained. In this specimen the chorda-mesodermal layer (ch. mes. 1.) has been established between the embryonic disc (em. disc) and the endoderm (end.). Amniogenesis has also been initiated as can be seen by the up-growing folds from the perimeter of the embryonic disc. These up-growing folds of the definitive amnion bring with them a layer of cytotrophoblast from the perimeter of the embryonic disc which will eventually underlie the syncytiotrophoblast roofing the embryonic disc when they unite mid-dorsally. 
PLATE 1
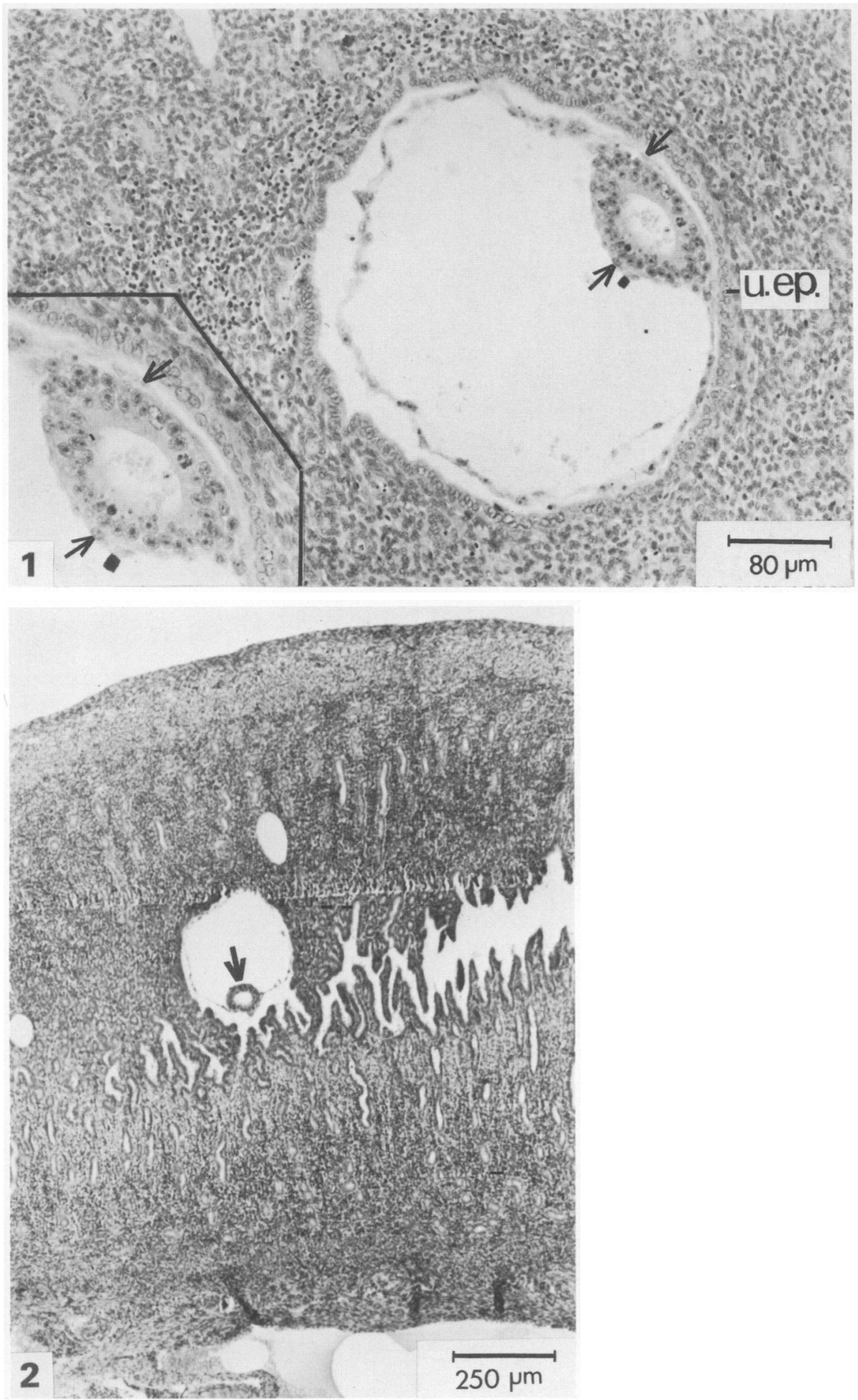

(Facing p. 320) 
PLATE 2
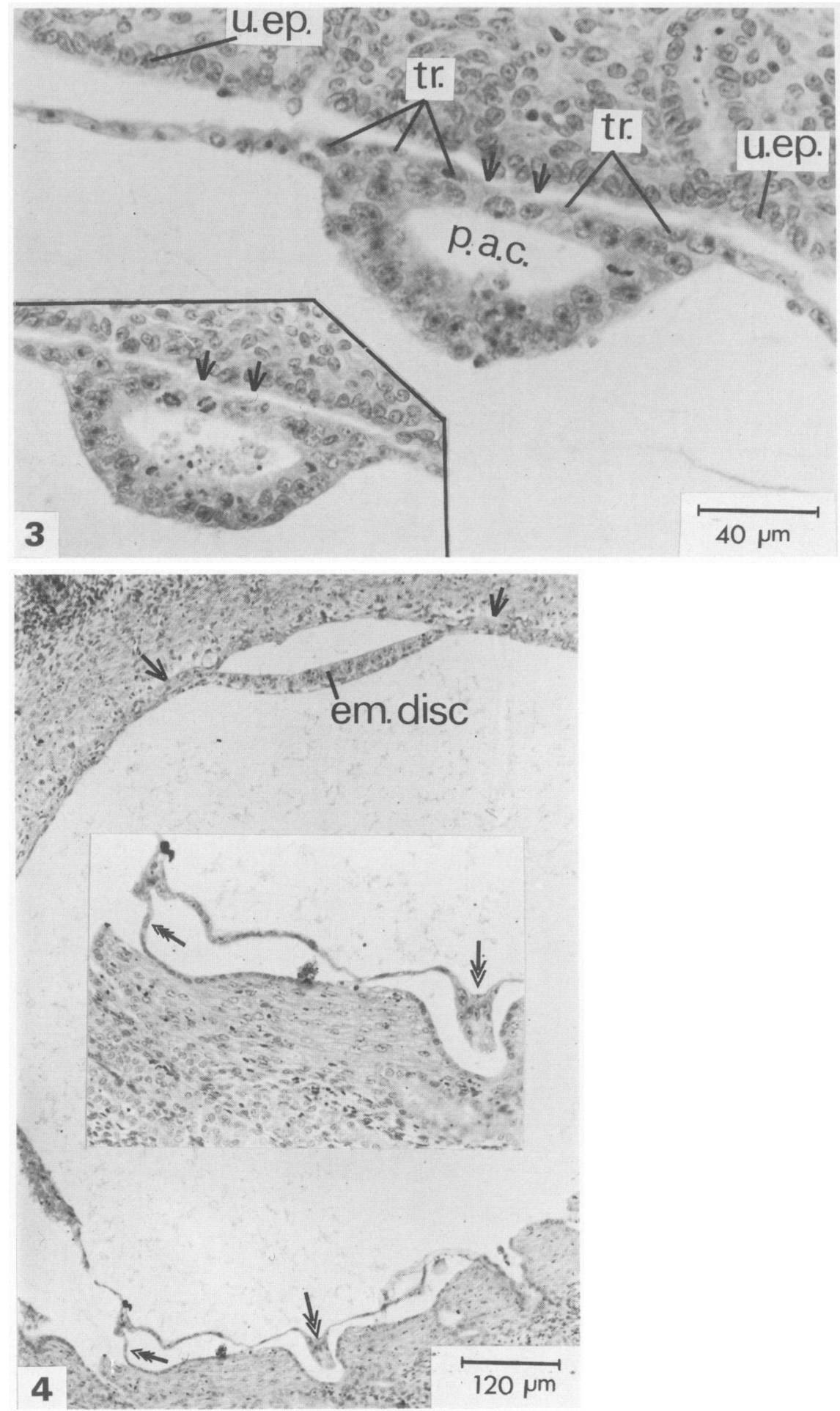
PLATE 3
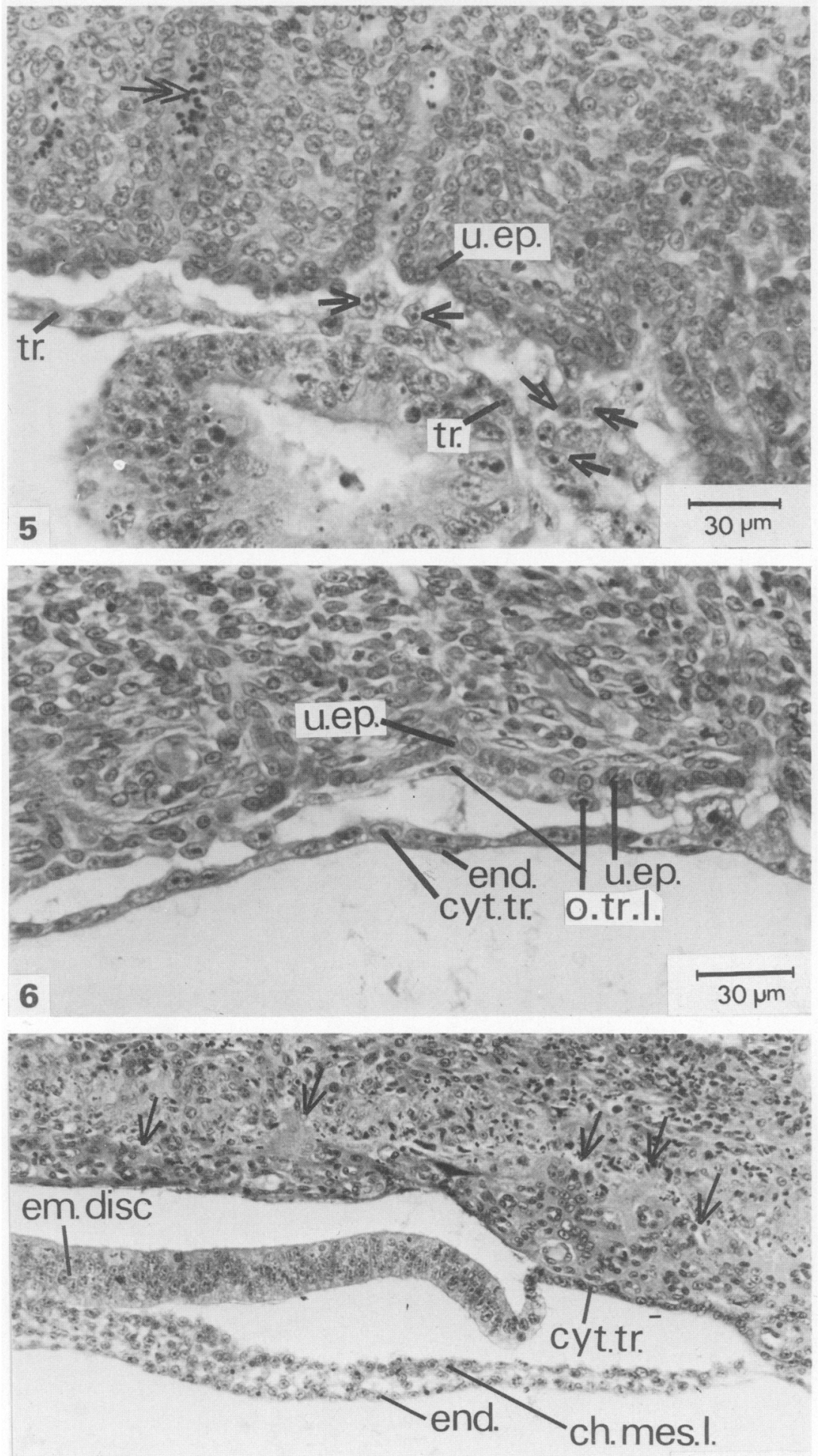
the uteri were embedded in Paraplast (composed of purified paraffin wax and plastic polymers of regulated molicular mass) and sectioned serially at $5 \mu \mathrm{m}$. The sections were stained with haemotoxylin and counter-stained with eosin.

\section{Results}

The blastocyst implanted only in the right uterine horn during the bilaminar stage. Implantation was superficial (see Pl. 1, Fig. 1; Pl. 2, Fig. 3) and the blastocyst was expanded within the uterine lumen. Orientation of the point of initial trophoblastic attachment, like the orientation of the embryonic disc, was antimesometrial.

During the preimplantation period the blastocyst became completely enclosed by uterine mucosa (Pl. 1, Fig. 1). This enclosure of the blastocyst was the result of a gradual thickening of the endometrium during the preimplantation period which resulted in the circumference of the uterine lumen gradually being reduced. Due to this action the uterine epithelium became fringed or scalloped, the uterine lumen became obliterated and the blastocyst surrounded by uterine epithelium (Pl. 1, Figs 1 and 2). At the time of implantation deterioration was observed in many of the uterine glands in that cellular debris and pycnotic nuclei were present in the gland lumina (see Pl. 3, Fig. 5). Destruction of the epithelial layer was eventually caused by the invading trophoblast cells. This final breakdown took place earlier on the antimesometrial side (Pl. 2, Fig. 4), and breakdown of the remainder of the epithelial layer was much accelerated in front of the advancing trophoblast.

Although no significant development occurred in the bilaminar blastocyst for most of the delay period, considerable activity was observed in the trophoblast layer of the blastocyst just before implantation. Penetration of the uterine endometrium involved only the trophoblast of the embryonic hemisphere. The trophoblast of the abembryonic hemisphere stayed relatively unchanged and only formed protrusions (papillae) corresponding with the opening of glands ( $\mathrm{Pl}$. 2, Fig. 4). On the embryonic hemisphere, however, shortly before penetration, the trophoblast cells began to proliferate, forming two parallel layers (Pl. 3, Fig. 6). This proliferation began at the inner cell mass area (PI. 3, Fig. 5) where the trophoblast cells proliferated haphazardly. A distinctive bilaminar arrangement was never observed over the inner cell mass and as there was no conspicuous degenerative activity of the trophoblast here, it appeared that the trophoblast layer overlying the inner cell mass became syncytial when the maternal tissue was penetrated. In this manner even the early embryonic disc was already roofed by syncytiotrophoblast. From the edge of the inner cell mass as far as the equator of the blastocyst the trophoblast became distinctly bilaminar before it began to penetrate the maternal tissue (Pl. 3, Fig. 6), and the blastocyst was therefore enveloped by an inner trophoblast layer or cytotrophoblast (i.e. the original trophoblast layer) and an outer trophoblast layer. The outer trophoblast cells penetrated any gland openings. The cellular arrangement of the cytotrophoblast (Pl. 3, Fig. 6) was maintained but the outer trophoblast layer became syncytial when the overlying epithelium had been destroyed and the endometrium penetrated (Pl. 3, Fig. 7). Later, with the formation of the true or definitive amnion, upgrowing folds from the perimeter of the embryonic disc brought with it a layer of cytotrophoblast to underlie the syncytiotrophoblast roofing the embryonic disc (Pl. 3, Fig. 7).

Just before and during the stage when the trophoblast layer of the embryonic hemisphere had divided into two layers, the inner cell mass, with its centrally situated primitive amniotic cavity, started to flatten, and the primitive amnion (which did not participate in the formation of the true or definitive amnion) became attenuated (Pl. 2, Fig. 3) and eventually broke away to expose the embryonic disc after the overlying syncytiotrophoblast had been established and penetration of the endometrium was well underway (PI. 2, Fig. 4). Shortly after establishment of the embryonic disc the primitive streak was formed through which the mesoderm cells migrated to give rise to the chorda-mesodermal layer resulting in the conceptus becoming trilaminate (PI. 3, Fig. 7).

The blastocyst expanded rapidly, mainly due to the enlargement of its cavity, just before and during trophoblastic invasion of the endometrium. This action resulted in progressively more of 
the right uterine horn, and eventually the left also, being occupied and stretched around the expanding blastocyst and developing embryo.

\section{Discussion}

Reproductive asymmetry, i.e. unilateral dominance of the ovary, the uterus or both, is common in chiropterans (Wimsatt, 1975). In miniopterine bats a contralateral dominance pattern exists in which ovulation nearly always occurs from the left ovary with pregnancy invariably in the right horn (Wimsatt, 1979). In the Natal clinging bat $95 \%$ of the ova are shed from the left ovary and all implantations occur only in the right uterine horn. Because of this strong asymmetry the right uterine horn of the bicornuate uterus is twice the length of the left one.

In most mammals, the zygote retains the zona pellucida while it is in the oviduct and for various lengths of time in the uterus (Blandau, 1949; review by Rasweiler, 1972, 1979). In some mammals, however, e.g. the phyllostomatid bats Glossophaga soricina and Carollia sp. (Rasweiler, 1972, 1974; De Bonilla \& Rasweiler, 1974) and probably also in the vampire bat Desmodus rotundus (Quintero \& Rasweiler, 1974), the zona pellucida is shed in the oviduct. In the Natal clinging bat breakdown of the zona pellucida occurs during the early stages of the unimplanted intrauterine life of the blastocyst, leaving it without a zona pellucida for the greater part of the unimplanted period, as also reported by Wallace (1978) for the bent-winged bat in New South Wales. The chorionic vesicle stage, following the suggestion of Wimsatt (1975) that this is a more appropriate term for a conceptus from at least the trilaminar stage onwards, is reached in Natal clinging bats only after implantation has occurred.

The orientation of the point of first trophoblastic attachment and the orientation of the embryonic disc were antimesometrial in these bats. The mechanism of orientation of the blastocyst is uncertain but presumably involves rotation of the blastocyst as a whole. However, some blastocysts in the present series had apparently failed to become properly orientated before enclosure by uterine epithelium (Pl. 1, Fig. 2). In such cases, migration of the inner cell mass, as suggested for mice (Kirby et al., 1967; Kirby, 1971), could take place.

In Natal clinging bats all the basic implantation characteristics are similar to those summarized by Wimsatt (1975) and Rasweiler (1979) for other vespertilionids so far investigated. Wallace (1978) reported that implantation "occurs uniformly on all sides of the uterus" in the New South Wales bent-wing bat but this interpretation is questionable since it is based on only one post-implanted embryo.

As in the miniopterine bats found in France and Australia (Da Costa, 1920; Richardson, 1977; Wallace, 1978) the uterine epithelium in Natal clinging bats appears to be much more persistent than in any of the other vespertilionids so far investigated. In the Natal bats destruction of this layer is caused by the trophoblast cells when they are actively starting to penetrate the endometrium on the antimesometrial side. The destructive role of the syncytiotrophoblast cells is clearly illustrated by the longer persistence of the epithelium layer on the mesometrial side where no syncytiotrophoblast occurs over the abembryonic hemisphere of the blastocyst. Cellular debris found within the primitive amniotic cavity consists of parts of the primitive amnion (Da Costa, 1920) and were commonly observed during the present study. The origin of this debris is not known. Van der Merwe (1980) suggested that it was the remains of the degenerating primitive amnion but in the present study there were no signs of degeneration of the primitive amnion. The primitive amnion merely became attenuated and so the debris found in the primitive amnion cavity may have resulted from the cavitation process.

\section{References}

Blandau, R.J. (1949) Observations on implantation of the guinea pig ovum. Anat. Rec. 103, 19-47.

Da Costa, A.C. (1920) Sur la formation de l'amnios chez

les Cheiropteres (Miniopterus schreibersii) et, en general, chez les mammiferes. Mems Soc. port. Sci. nat. Sér. Biol. 3, 1-51. 
Daniel, J.C. (1970) Dormant embryos of mammals. Biol. BioScience 20, 411-415.

De Bonilla, H. \& Rasweiler, J.J. (1974) Breeding activity, preimplantation development, and oviduct histology of the short-tailed fruit bat, Carollia, in captivity. Anat. Rec. 179, 385-404.

Fleming, H. (1971) Artibeus jamaicensis: delayed embryonic development in a Neotropical bat. Science, N.Y. $171,402-404$.

Kirby, D.R.S. (1971) Blastocyst-uterine relationship before and during implantation. In The Biology of the Blastocyst, pp. 393-412. Ed. R. J. Blandau. University of Chicago Press.

Kirby, D.R.S., Potts, D.M. \& Wilson, I.B. (1967) On the orientation of the implanting blastocyst. J. Embryol. exp. Morph. 17, 527-532.

Mossman, H.W. (1971) Orientation and site of attachment of the blastocyst: a comparative study. In The Biology of the Blastocyst, pp. 49-57. Ed. R. J. Blandau. University of Chicago Press.

Potts, M. (1969) The ultrastructure of egg implantation. Adv. Reprod. Physiol. 4, 241-267.

Quintero, F. \& Rasweiler, J.J. (1974) Ovulation and early embryonic development in the captive vampire bat, Desmodus rotundus. J. Reprod. Fert. 41, 265-273.

Rasweiler, J.J. (1972) Reproduction in the long-tongued bat, Glossophaga soricina. I. Preimplantation development and histology of the oviduct. J. Reprod. Fert. 31, 249-262.

Rasweiler, J.J. (1974) Reproduction in the long-tongued bat, Glossophaga soricina. II. Implantation and early embryonic development. Am. J. Anat. 139, 1-36.
Rasweiler, J.J. (1979) Early embryonic development and implantation in bats. J. Reprod. Fert. 56, 403-416.

Richardson, E.G. (1977) The biology and evolution of the reproductive cycle of Miniopterus schreibersii and M. australis (Chiroptera: Vespertilionidae). J. Zool., Lond. 183, 353-375.

van der Merwe, M. (1979) Foetal growth curves and seasonal breeding in the Natal clinging bat Miniopterus schreibersi natalensis. S. Afr. J. Zool. 14, 17-21.

van der Merwe, M. (1980) Delayed implantation in the Natal clinging bat Miniopterus schreibersi natalensis (A. Smith, 1834). In Proc. 5th Int. Bat Res. Conf, pp. 113-123. Eds D. E. Wilson \& A. L. Gardner. Lubbock, Texas.

Wallace, G.I. (1978) A histological study of the early stages of pregnancy in the bent-winged bat (Miniopterus schreibersii) in north-eastern New South Wales, Australia $\left(30^{\circ} 27^{\prime}\right.$ S). J. Zool., Lond. $185,519-537$.

Wimsatt, W.A. (1969) Some interrelations of reproduction and hibernation in mammals. Symp. Soc. exp. Biol. 23, 511-549.

Wimsatt, W.A. (1975) Some comparative aspects of implantation. Biol. Reprod. 12, 1-40.

Wimsatt, W.A. (1979) Reproductive asymmetry and unilateral pregnancy in Chiroptera. $J$. Reprod. Fert. 56, 345-357. 